\title{
Sensor based extended floating bicycle data (xFBD) analysis
}

\author{
Krisp J.M. ${ }^{\mathrm{a}, ~}{ }^{\text {, }}$ Kalinic M. ${ }^{\text {a }}$, Röger C. ${ }^{\text {a }}$, Keler, A. ${ }^{\text {b }}$ \\ ${ }^{a}$ University of Augsburg, Institute of Geography, Alter Postweg 118, 86159 Augsburg, Germany, jukka.krisp@geo.uni-augsburg.de, \\ maja.kalinic@geo.uni-augsburg.de, christian.roeger@geo.uni-augsburg.de \\ ${ }^{b}$ Technische Universität München, Ingenieurfakultät Bau Geo Umwelt, Lehrstuhl für Verkehrstechnik, Arcisstr. 21, 80333 München, \\ andreas.keler@tum.de \\ * Corresponding author
}

Keywords: extended floating bicycle data (xFBD), spatial analysis, fuzzy logic, sensors

\section{Abstract:}

Many initiatives and city administrations in Germany look for ways to improve their bicycle infrastructure. An improvement is determined by many factors, including financial resources, existing infrastructure and administrative issues. It also seems unclear, what are measures of a good bicycle infrastructure. Is the amount of bicycle lanes? The quality of these lanes? An important question seems to be, what determines a pleasant bike ride experience?

Our aim is to investigate the possibility to measure a multiple sensor data on a bicycle and to detect parameters that indicate a "pleasant" bicycle ride from this sensor data. Generally, a "pleasant" ride is defined as a ride "giving a sense of happy satisfaction or enjoyment". Still the definition seems to vary also on the person riding the bike, so a clear definition of the concept is still an open question. The sensor data is collected in a high frequency for every position along a test track. In the analysis, we follow a data driven approach classifying the detected values into fuzzy membership functions. In particular, the case study includes a bicycle ride within the university area of Augsburg. Sensors record data with a one-second interval. The initial dataset is compiled using all raw data. Our analysis does consider selected parameters for the "pleasantness" of bicycle ride. Our sensor data records a variety of different parameters listed in table 1. In particular, we use a multi sensor array based on an Arduino Nano microcontroller. We attach various sensors, including a NEO-6M GPS, a PMS3003 Particulate Matter sensor, a DHT22 Temperature\& Humidity sensor and an MH-Z19b carbon dioxide sensor. For logging sensor data, we use a micro SD reader/writer. All the utilized sensors are stored in a shock- and waterproof box. Except of the GPS, every sensor is placed within a chamber ventilated by fans in order to protect them from direct sun and rain influence. Figure 1 shows the multi sensor array within the sensor box.

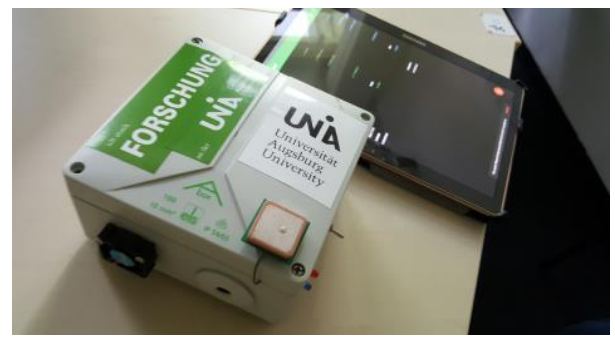

Figure 1 a. Box including the sensor array

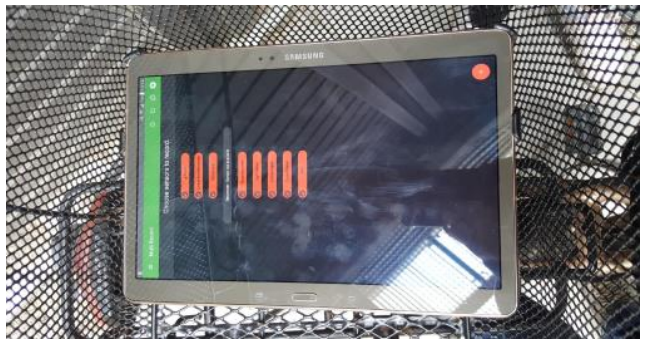

Figure $1 \mathrm{~b}$. Pad running the physics toolbox app attached to a test bicycle

The conceptual setup is referred to as recording "extended floating bicycle data" or "xFBD". Parameters obtained from the multi sensor array are shown in Table 1.

\begin{tabular}{|l|l|}
\hline Parameter & Description \\
\hline ID & Point ID \\
\hline Millis & Milliseconds since start \\
\hline Latitude & Latitude in degrees \\
\hline Longitude & Longitude in degrees \\
\hline Datetime & Current date and time \\
\hline Temperature & Temperature in Celsius degrees \\
\hline Humidity & Humidity in percent \\
\hline PM01 & Particulate Matter of sizes $<1 \mu \mathrm{m}$ in $\mu \mathrm{g} / \mathrm{m}^{3}$ \\
\hline PM2.5 & Particulate Matter of sizes $<2.5 \mu \mathrm{m}$ in $\mu \mathrm{g} / \mathrm{m}^{3}$ \\
\hline PM10 & Particulate Matter of sizes $<10 \mu \mathrm{m}$ in $\mu \mathrm{g} / \mathrm{m}^{3}$ \\
\hline CO2 & Carbon Dioxide in parts per million $(\mathrm{ppm})$ \\
\hline
\end{tabular}


Every record point has its own unique ID represented by an iterator counting from 1 . The millis parameter depicts the time in milliseconds since the start of the recording. Latitude, Longitude and date-time values obtained from the GPS sensor give the record points a spatio-temporal reference. Further we record temperature in degrees Celsius and humidity in percent. Particulate Matter readings are grouped according to particle sizes. PM01 describes particles with a diameter smaller than $1 \mu \mathrm{m}$. PM25 values include particles smaller than $2.5 \mu \mathrm{m}$. PM10 includes particles smaller than $10 \mu \mathrm{m}$. Finally, we record carbon dioxide (CO2) in parts per million (ppm). A mobile phone or a pad includes a number of sensors.

Additionally, we include data acquired from smartphone sensors attached to a bicycle. These data points are recorded with the Vieyra Software app "physics toolbox", which registers all smartphone sensor inputs for defined locations in a defined interval. Selected parameters recorded are listed in the following table.

\begin{tabular}{|l|l|}
\hline Parameter & Description \\
\hline Speed_____s & Velocity in meters per second \\
\hline gFx & G-Force (x-axis) \\
\hline gFy & G-Force (y-axis) \\
\hline Ax & Acceleration (x-axis) \\
\hline Az & Acceleration (z-axis) \\
\hline L & Light intensity \\
\hline
\end{tabular}

The test tracks includes three test-rides in the University of Augsburg area. Two tracks are individually instigated. Figure 2 shows a plot of the test tracks a and b.

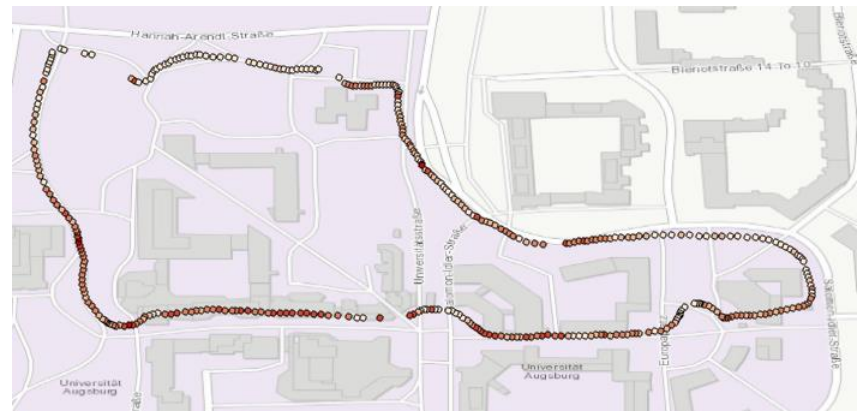

Figure 2 a. Track a

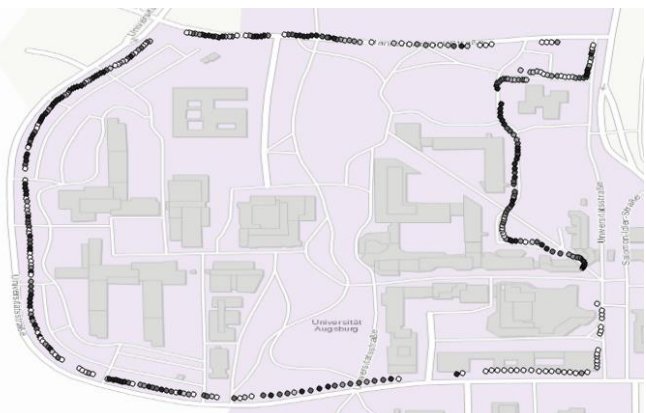

Figure 2 b. Track b

Recorded data generated for this study is available at https://github.com/roegechr/xFBD. The track a includes 138.404 points, track b 155.032 points. The data points show some missing records as the GPS positioning is not accurate in some parts of the track.

This type of data requires specific methods to analyse and visualize multi-variate spatial datasets. In our case we investigate the application of a fuzzy-logic modelling approach. As Kalinic and Krisp (2019) state, traditional analytical techniques have often found to be non-effective when dealing with problems in which the dependencies between variables are too complex or vaguely defined. Since the fuzzy set theory recognizes the vague boundary that exists in some sets, fuzzy inference model can be used in order to properly model the continuum from "pleasantness" to "unpleasantness" of a bicycle ride. Fuzzy inference is the process of formulating a given input to an output using fuzzy logic (Fullér and Zimmermann 2018). The process itself involves several phases - defining and fuzzyfying input parameters, applying fuzzy rules and operators, applying implication method, applying aggregation method and (if needed) defuzzification (Kalinic and Krisp 2019).

As a test case, the initial fuzzy model includes two input parameters - temperature and humidity, derived from the bicycle sensor data and one output parameter - (level of) bicycle ride pleasantness. Defining input parameters is crucial and challenging task in fuzzy modelling. It requires both knowledge and experience in specific field (Klir and Yuan, 1995), but most importantly, it depends on available data. The bicycle sensor data gathered for this project has two interesting parameters - humidity and temperature, which we use as a fuzzy model input parameters. Both parameters are fuzzified with three full triangle membership functions. These neighbouring membership functions overlap with each other by $25 \%$ to enable that input points (temperature and humidity readings) on the universe of discourse belong to at least one but not more than two membership functions. Both input parameters are labeled with three linguistic variables respectively low, normal and high. Further, we assign if - then rules to map input variables into an output fuzzy set. We select nine if then rule combinations in. All the rules are connected with AND operator meaning that minimum condition has to be met. Our initial results consider only one variable - (level of) bicycle ride pleasantness, which is described as pleasant, less pleasant, unpleasant and very unpleasant ride. These linguistic variables are further defuzzified into four levels (1-4) which show very unpleasant, unpleasant, less pleasant and pleasant ride respectively. Figure 3 shows detected levels of bicycle ride pleasantness at the location where sensor bicycle data is gathered. 


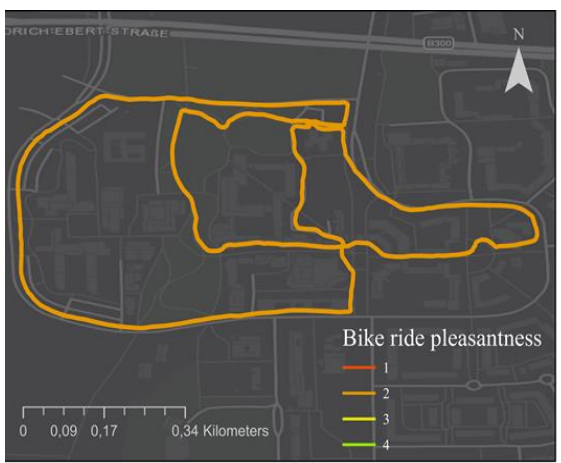

Figure 3.. Initial test results for humidity and temperature - detected levels of bicycle ride pleasantness, with 1 showing the very unpleasant, 2 - unpleasant, 3 - less pleasant and 4 pleasant ride

The results of the initial case study reflect the possibility of analysing bicycle ride in their relation to "pleasantness". In this particular case, the data does not show differences in the tracks. The measurement days are somewhat grey with little variation of temperature and humidity in the study area. Therefore, the output shows an unpleasant bicycle ride for all points. These case study results are expected, still the conceptual application of a fuzzy logic approach to analyse the sensor data is successful.

The concept turns out to be somewhat case specific. It seems to be difficult to find generally valid indicators for a pleasant bicycle ride. Results reflect a continuum that possibly de-fuzzyfies the road sections into a "pleasant", "less pleasant", "unpleasant" \& "very unpleasant" bicycle ride. This information can be used for evaluating the current road network in relation to bicycle usage and for planning extension to the current bicycle lane network. The inclusion of dynamic parameters, like weather, light noise etc is highly depended on the time of the measurement. A very large number of sensor recordings would help to find an average value for these parameters for each specific road section. The initial raw data collected includes a large number of samples and measures. Not all of these records are relevant or related to a "pleasant" bicycle ride. Nevertheless, a sensor driven approach might help to investigate the relations between clusters in the different features.

\section{References}

Fullér, R., and H. Zimmermann. 2018. 'Fuzzy Reasoning for Solving Fuzzy Mathematical Programming Problems', Fuzzy Sets and Systems, 60: 121-33.

Kalinic, M., and J.M. Krisp. 2019. 'Fuzzy inference approach in traffic congestion detection', Annals of GIS.

Rötzer, M., J. Kadriu, M. Duchêne, M. Essig, and J.M. Krisp. "Sensor-based analysis of bicycle lane quality." In Proceedings Towards Human Scale Cities -Open And Happy. 15th biennial NECTAR conference, 5-7 June 2019, Helsinki, Finland, p. 155-157, ISSN-L 1798-7938.

Handy, S., van Wee, B., \& Kroesen, M. (2014). Promoting Cycling for Transport: Research Needs and Challenges. Transport Reviews, 34(1), 4-24. https://doi.org/10.1080/01441647.2013.860204

Klir G J and Yuan B (1995). Fuzzy Sets and Fuzzy Logic: Theory and Applications. Prentice Hall PTR, 1995.

Martens, K. (2007). Promoting bicycle-and-ride: The Dutch experience. Transportation Research Part A: Policy and Practice, 41(4), 326-338. https://doi.org/10.1016/j.tra.2006.09.010

Nello-Deakin, S., \& Nikolaeva, A. (2020). The human infrastructure of a cycling city: Amsterdam through the eyes of international newcomers. Urban Geography, 1-23. https://doi.org/10.1080/02723638.2019.1709757

Nielsen, T. A. S., \& Skov-Petersen, H. (2018). Bicycleability - Urban structures supporting cycling. Effects of local, urban and regional scale urban form factors on cycling from home and workplace locations in Denmark. Journal of Transport Geography, 69, 36-44. https://doi.org/10.1016/j.jtrangeo.2018.04.015

Pucher, J., \& Buehler, R. (2017). Cycling towards a more sustainable transport future. Transport Reviews, 37(6), 689694. https://doi.org/10.1080/01441647.2017.1340234

Snizek, B., Sick Nielsen, T. A., \& Skov-Petersen, H. (2013). Mapping bicyclists' experiences in Copenhagen. Journal of Transport Geography, 30, 227-233. https://doi.org/10.1016/j.jtrangeo.2013.02.001

Tenkanen, H., \& Toivonen, T. (2020). Longitudinal spatial dataset on travel times and distances by different travel modes in Helsinki Region. Second Review Round in Scientific Data. 